Research Article

\title{
Experimental Investigations on Rheological Properties of Mudstone in Kilometer-Deep Mine
}

\author{
Jinglong Jia $\mathbb{D}^{1,2}$ Fenghai Yu $\mathbb{D}^{1,2}$ Yunliang Tan $\mathbb{D D}^{1,2}$ and Xuepeng Gao $\mathbb{D}^{3}$ \\ ${ }^{1}$ State Key Laboratory of Mining Disaster Prevention and Control Cofounded by Shandong Province and the \\ Ministry of Science and Technology, Shandong University of Science and Technology, Qingdao 266590, China \\ ${ }^{2}$ National Demonstration Center for Experimental Mining Engineering Education, \\ Shandong University of Science and Technology, Qingdao 266590, China \\ ${ }^{3}$ Key Laboratory of Ministry of Education on Safe Mining of Deep Metal Mines, Northeastern University, \\ Shenyang 110819, China
}

Correspondence should be addressed to Fenghai Yu; skdyfh@sdust.edu.cn

Received 12 October 2020; Revised 30 December 2020; Accepted 9 January 2021; Published 23 January 2021

Academic Editor: Hualei Zhang

Copyright (c) 2021 Jinglong Jia et al. This is an open access article distributed under the Creative Commons Attribution License, which permits unrestricted use, distribution, and reproduction in any medium, provided the original work is properly cited.

The soft rock roadway in deep high-stress environment has the problems of strong rheology and large deformation. Based on the analysis of the stress distribution of the surrounding rock of the roadway in a kilometer-deep mine, rheological tests under different stress paths are carried out for mudstone in a kilometer-deep mine. The rheological deformation curve, damage characteristics, and change rule of the main mechanical parameters of mudstone under different stress conditions are studied. The results show the following: (1) the peak strength of the triaxial compression of mudstone is closely related to confining pressure, and, with increasing confining pressure, the confining pressure effect decreases gradually; (2) the strain increases slowly under uniaxial loading, and, with increasing axial pressure, the velocity of rheological deformation increases nonlinearly, and the amount of mudstone deformation increases with time; (3) under the condition of unloading confining pressure with constant axial pressure, with decreasing confining pressure, the instantaneous axial and radial strains of mudstone specimen increase nonlinearly, the rheological strain and velocity of mudstone increase gradually, and the lateral rheological strain is close to the axial rheological strain; and, (4) in the unloading confining pressure with axial compression triaxial test, with increasing deviating stress, the axial and radial instantaneous strain increments of mudstone decrease gradually, the lateral strain and rheological velocity of mudstone increase gradually, and the lateral strain is approximately 2.05 times the axial strain. These conclusions reveal the rheological characteristics of the mudstone under different surrounding rock conditions and provide a theoretical basis for the excavation deformation and support control of roadways.

\section{Introduction}

The rheological deformation and destruction of rock have important effects in the deep rock mass. The surrounding rock of a deep roadway has a high sensitivity to the influence of mining. The surrounding rock behavior after deep roadway excavation has the characteristics of strong dynamic stress and long-term strong rheology $[1,2]$.

The in situ stress state of a kilometer-deep mine is mainly vertical stress, and the high-stress distribution of deep surrounding rock has an important influence on rheological deformation of soft rock roadway [3, 4]. In terms of theoretical research, Liu et al. [5] showed that a deep rock mass shows significant nonlinear mechanical characteristics under the influence of mining disturbance rather than a single linear increase or decrease. Gao et al. [6] proposed the concept of the neighborhood of rock strength limit and pointed out that when the stress state of rock approaches its strength limit, the rock will behave rheologically. In terms of deep rock rheological test research, Yuan et al. [7] used unloading rheological tests on sandy mudstone to show that different initial unloading confining pressure affects the time of the rheological failure of 
rock and the starting time of accelerated rheology. Wang [8] considered the disturbance effect in a rock rheological experiment. Wang et al. [9] carried out an unloading confining pressure with constant axial pressure triaxial test of a deep coal body and found that the creep deformation of the coal body decreased with increasing confining pressure under the same deviating stress condition. Jing et al. [10] carried out a largescale physical model test of a deep roadway using a self-developed simulation test system of the entire process of the structural instability of deep underground engineering and obtained the bearing characteristics and deformation and fracture evolution characteristics of different anchorage structures of a roadway's surrounding rock. In terms of rheological numerical simulation research, Peng et al. [2] studied the large-deformation question of the surrounding rock of a roadway in a kilometer-deep mine through a similar simulation experiment. Influenced by the coal seam dip angle, the destruction first occurred at the bottom corner and the arch shoulder of the roadway. Wang et al. [11] studied the influence of unloading on the failure of deep rock through a true triaxial test. Zhao et al. [12, 13] established a nonlinear BKS creep damage model and a viscoelastic plastic BK-MC anchorage model for rock mass with an anchor considering the damage effects and applied them to the development of numerical simulation software.

The above works have studied the rheology of deep soft rock from different angles. The rheology of soft rock mass is an important reason for the large deformation of surrounding rock in a deep roadway $[14,15]$. For a soft rock roadway in a kilometer-deep mine under the condition of high crustal stress, the surrounding rock stress shows different combination forms of horizontal unloading and vertical loading in different mining influence stages, and the differential influence on the internal rheological deformation characteristics and failure of the surrounding rock needs further study. Therefore, in this paper, the mudstone in China's Kouzidong Coal Mine is taken as the research object, triaxial rheological tests under different confining pressure unloading and axial compressing conditions are carried out, and the rheological characteristics of mudstone in a kilometer-deep mine under different stress environments are studied, revealing the different influence of mudstone rheology on the internal rheological deformation and failure of surrounding rock in different periods and providing references for soft rock roadway support and surrounding rock control.

\section{Experimental Method}

2.1. Test Basis. According to the different development stages of the surrounding rock stress after the excavation of the strong mining roadway in the kilometer-deep mine, Kang et al. [1] proposed the lateral unloading and verticalloading stress path model of the surrounding rock shown in Figure 1. It can be seen in Figure 1 that the lateral unloading of surrounding rock caused by roadway excavation mainly occurs in the period affected by driving, and the vertical loading occurs in the periods affected by driving and by mining. Period I indicated that the vertical stress concentration of the surrounding rock occurs simultaneously with the lateral unloading. Period II indicated that the lateral unloading occurs under the condition of vertical stress stability. In period III, $\sigma_{1}$ increases and $\sigma_{3}$ remains static, indicating that the lateral unloading of surrounding rock is basically finished, but the vertical loading still exists due to the influence of mining.

2.2. Conventional Triaxial Test Scheme. The sampling site of the test specimens is located in Kouzidong Coal Mine. As shown in Figure 2, the standard cylindrical rock test piece was processed and prepared in the laboratory. The uniaxial compressive strength of this group of mudstone specimens is $33.52-40.61 \mathrm{MPa}$, with an average of $37.29 \mathrm{MPa}$, and the elastic modulus is $4.69-8.14 \mathrm{GPa}$, with an average of $6.41 \mathrm{GPa}$.

As shown in Figure 3, the triaxial compression test is conducted using an RLJW-2000 rock servo test machine. The test equipment is composed of axial loading system, confining pressure system, shear system, control system, computer system, and so on. It can complete the measurement of elastic modulus, Poisson's ratio, peak strength, residual strength, and other parameters of rocks under different confining pressures. The axial loading is controlled by displacement, and the loading rate is $0.25 \mathrm{~mm} / \mathrm{min}$. The specific test scheme is shown in Table 1.

2.3. Rheological Test Scheme. According to the stress path of the surrounding rock of the kilometer-deep mine, three rheological test schemes are designed to study the rheological properties of mudstone under different horizontal and vertical stress environments.

(1) Uniaxial loading rheological test

An RLJW-2000 rock servo testing machine was used for the rheological tests of mudstone. The scheme of the uniaxial loading rheological tests of mudstone is shown in Table 2. The total loading time of each grade was $6 \mathrm{~h}$.

(2) Unloading confining pressure with constant axial pressure triaxial test

The scheme of the unloading confining pressure with constant axial pressure triaxial test of mudstone is shown in Table 3 . The total loading and unloading times of each grade were $6 \mathrm{~h}$.

(3) Unloading confining pressure with axial compression triaxial test

The scheme of the unloading confining pressure with the axial compression triaxial test of mudstone is shown in Table 4 . The total loading and unloading times of each grade were $6 \mathrm{~h}$.

\section{Results}

3.1. Confining Pressure Effect. The triaxial compression test results of mudstone under a confining pressure of 5-20 MPa are shown in Table 5. The triaxial compression stress-strain 


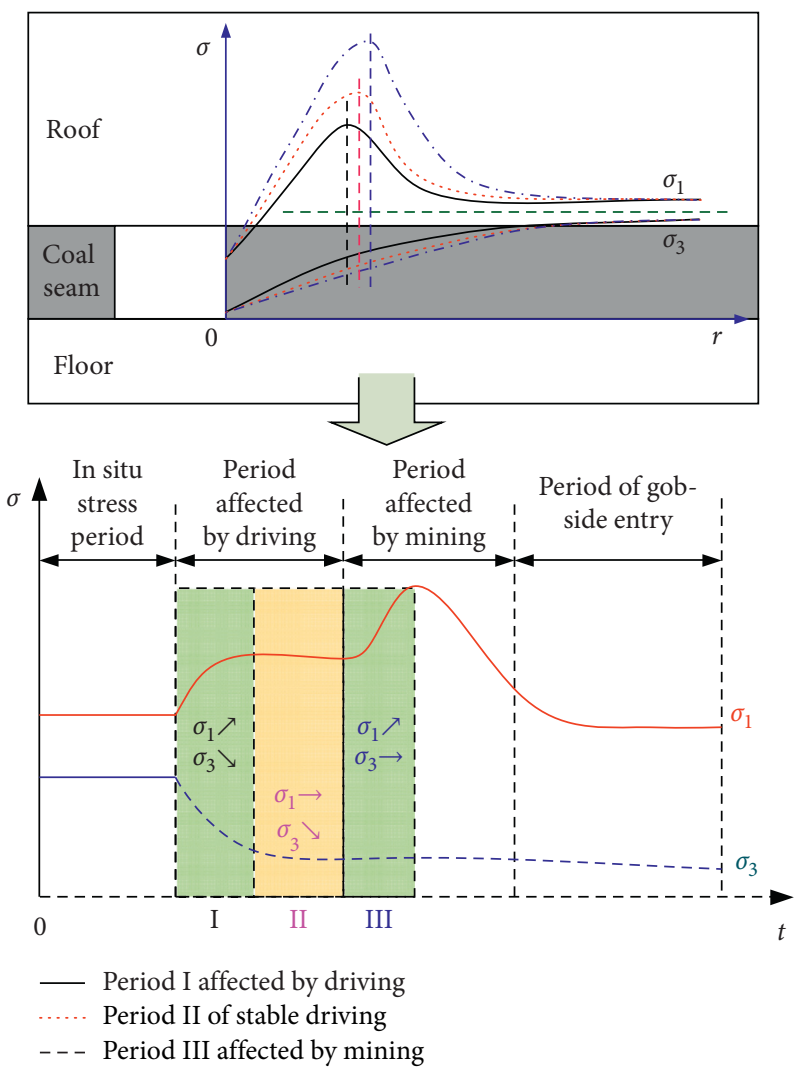

FIgURE 1: Conceptual model showing lateral-unloading and vertical-loading stress paths during roadway service life [1].

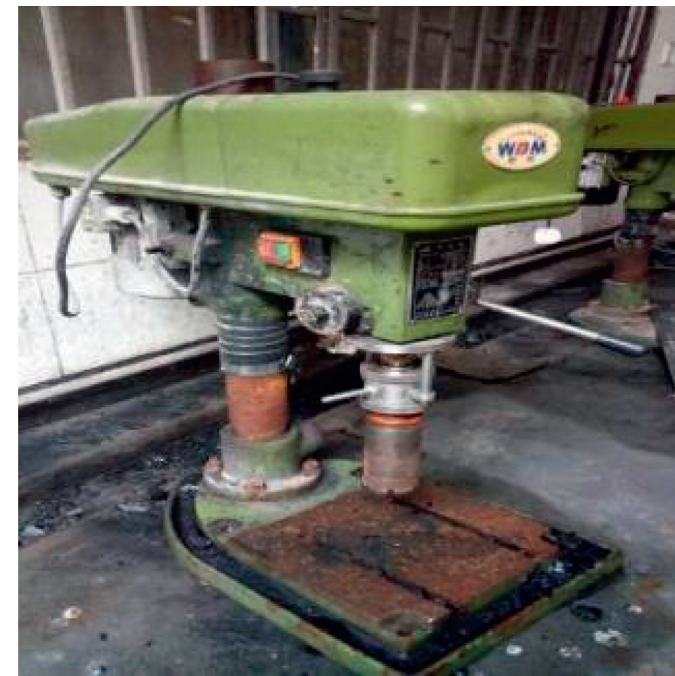

(a)

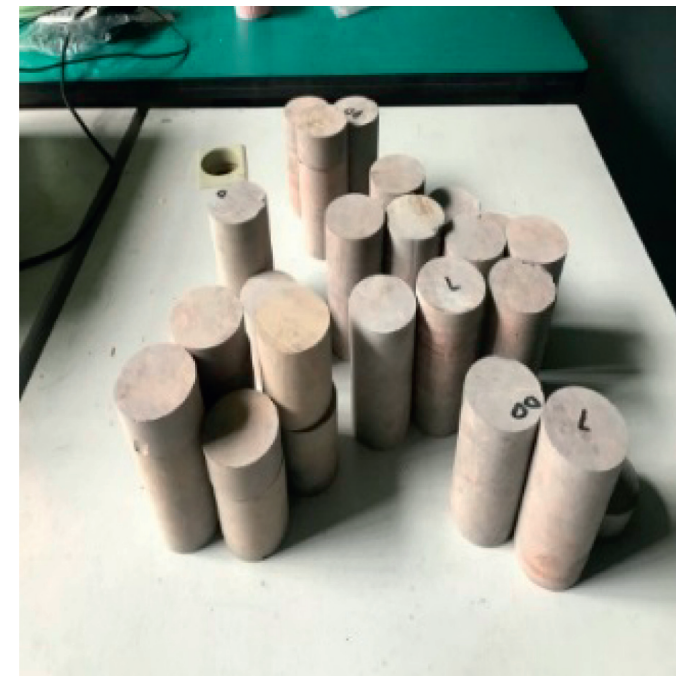

(b)

Figure 2: Mudstone specimen preparation. (a) Core-drilling machine. (b) Mudstone specimens.

curve of mudstone is shown in Figure 4. According to the Mohr-Coulomb criterion, the cohesion of mudstone is 16.5 $\mathrm{MPa}$ and the internal friction angle is $42.9^{\circ}$. It could be seen in Figure 5 that the fracture mode of the mudstone triaxial test specimen was mainly shear failure with a single section. With increasing confining pressure, the angle between the main fracture surface and maximum principal stress increases, and the fracture surface becomes increasingly flatter. As shown in Figure 4, compared with uniaxial compression, the postpeak stress of the triaxial compression specimen decreases slowly, and the reduction is slower and the residual stress is greater with increasing confining pressure. The mudstone can maintain a larger bearing capacity under high confining pressure. 


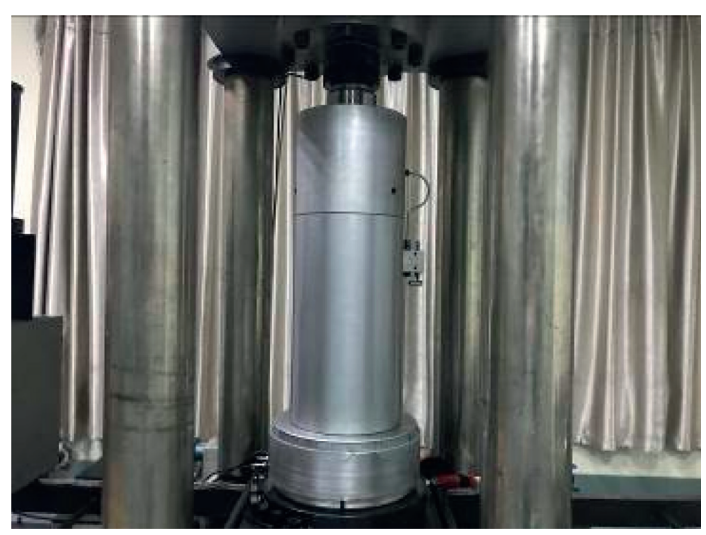

FIgURE 3: Loading of triaxial compression test.

TABLE 1: Conventional triaxial compression test scheme.

\begin{tabular}{lcccc}
\hline Number & A1 & A2 & A3 & A4 \\
\hline$\sigma_{3}(\mathrm{MPa})$ & 5 & 10 & 15 & 20 \\
\hline
\end{tabular}

TABLE 2: Uniaxial loading rheological test scheme.

\begin{tabular}{lcccccc}
\hline Load classification & I & II & III & IV & V & VI \\
\hline$\sigma_{1}(\mathrm{MPa})$ & 24 & 28 & 32 & 36 & 38 & 40 \\
\hline
\end{tabular}

TABLE 3: Unloading confining pressures with constant axial pressure triaxial test scheme.

\begin{tabular}{lcccccc}
\hline Load classification & I & II & III & IV & V & VI \\
\hline$\sigma_{1}(\mathrm{MPa})$ & 60 & 60 & 60 & 60 & 60 & 60 \\
$\sigma_{3}(\mathrm{MPa})$ & 20 & 15 & 10 & 8 & 5 & 3 \\
$\sigma_{1}-\sigma_{3}(\mathrm{MPa})$ & 40 & 45 & 50 & 52 & 55 & 57 \\
\hline
\end{tabular}

TABLE 4: Unloading confining pressures with axial compression triaxial test scheme.

\begin{tabular}{lccccccc}
\hline Load classification & I & II & III & IV & V & VI & VII \\
\hline$\sigma_{1}(\mathrm{MPa})$ & 30 & 40 & 50 & 55 & 60 & 65 & 65 \\
$\sigma_{3}(\mathrm{MPa})$ & 20 & 15 & 10 & 8 & 5 & 3 & 2 \\
$\sigma_{1}-\sigma_{3}(\mathrm{MPa})$ & 10 & 25 & 40 & 47 & 55 & 62 & 63 \\
\hline
\end{tabular}

To compare the influence of confining pressure $\sigma_{3}$ on triaxial strength, the confining pressure effect coefficient $\beta=\left(\sigma_{1}-\sigma_{c}\right) / \sigma_{3}$ is defined, where $\sigma_{1}$ is the peak stress, $\sigma_{3}$ is the confining pressure, and $\sigma_{\mathrm{c}}$ is the uniaxial compressive strength. Based on the above test results, the relationship curve of the confining pressure effect under different confining pressures is shown in Figure 6 and the corresponding calculation values are shown in Table 6.

It can be seen in Figure 6 and Table 6 that the effect of confining pressure on the strength of mudstone decreases gradually, indicating that, with increasing confining pressure, the increase of peak compressive strength decreases gradually. The results showed that the influence of confining pressure on the increase of strength decreases with the transition from brittleness to ductility and that the relationship between triaxial compressive strength and confining pressure is nonlinear. When confining pressure is present, the greater the confining pressure is, the slower the decrease is, and the greater the residual stress is. This indicates that confining pressure effect coefficient may reflect the influence of confining pressure on the rock strength. In the field engineering, the surrounding rock state can be inferred by monitoring the confining pressure. In addition, the stress conditions of the surrounding rock can be improved by supporting means, reducing the influence of the confining pressure effect coefficient on the deformation of the surrounding rock, and improving the safety of the field engineering.

\subsection{Rheological Characteristics}

3.2.1. Uniaxial Loading. The results of the uniaxial loading rheological test of mudstone are shown in Figure 7. With increasing grading load, the strain increases slowly, and, with increasing axial pressure, the rheological deformation speed increases nonlinearly. When the grading load increases to $40 \mathrm{MPa}$, the specimen reached its uniaxial compressive strength limit value, and the crack penetrates rapidly from the end to the middle. There are many cracks and the surface of the broken mud falls off. The specimen suffers from oblique splitting failure and has the characteristics of lateral expansion. Mudstone is prone to slow rheological deformation in the shallow part under the action of excavation disturbance stress, which will cause large deformation of the surrounding rock as time increases.

3.2.2. Unloading Confining Pressure with Constant Axial Pressure. The unloading confining pressure with constant axial pressure triaxial test results of mudstone is shown in Figure 8. A high-level confining pressure has an inhibitory effect on the axial and lateral rheology of rock, and the rheological amount of rock is small. With the gradual decrease of confining pressure, the axial and lateral instantaneous strains of a mudstone specimen increase nonlinearly, the rheological strain and rheological speed of mudstone increase gradually, and the lateral rheological amount is basically the same as the axial rheological amount. The 
TABle 5: Triaxial test results for mudstone.

\begin{tabular}{lccccc}
\hline $\begin{array}{l}\text { Specimen } \\
\text { number }\end{array}$ & $\begin{array}{c}\text { Confining pressure } \\
(\mathrm{MPa})\end{array}$ & $\begin{array}{c}\text { Compressive strength } \\
(\mathrm{MPa})\end{array}$ & $\begin{array}{c}\text { Elastic modulus } \\
(\mathrm{GPa})\end{array}$ & $\begin{array}{c}\text { Cohesion } \\
(\mathrm{MPa})\end{array}$ & $\begin{array}{c}\text { Internal friction angle } \\
\left({ }^{\circ}\right)\end{array}$ \\
\hline A1 & 5 & 68.27 & 17.70 & & \\
A2 & 10 & 90.40 & 21.56 & 16.5 & 42.9 \\
A3 & 15 & 106.41 & 24.79 & & \\
A4 & 20 & 128.43 & 29.48 & & \\
\hline
\end{tabular}

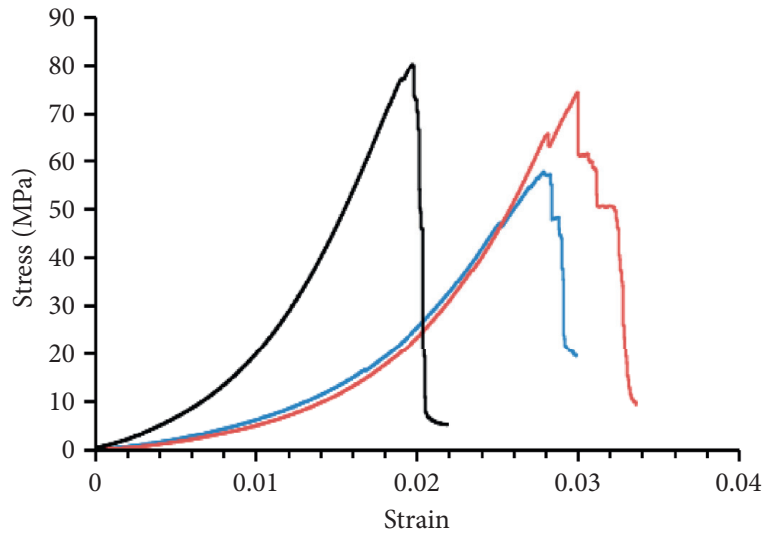

(a)

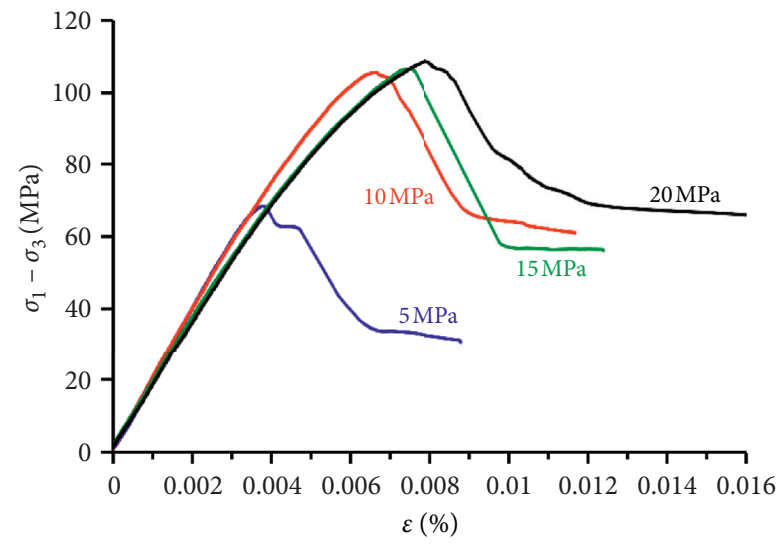

(b)

FIgURE 4: Stress-strain curves of mudstone. (a) Uniaxial compression. (b) Triaxial compression.
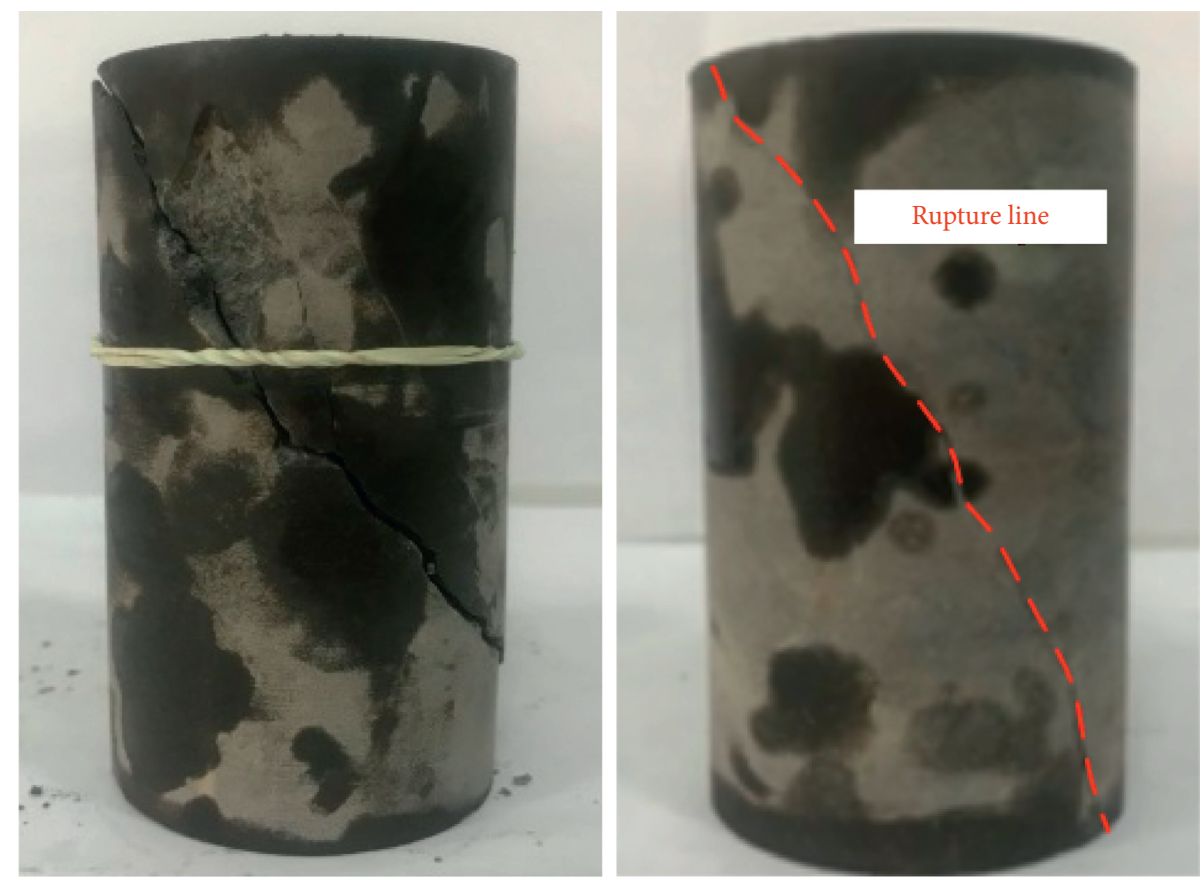

Figure 5: Fracture form of mudstone specimen in a triaxial compression test.

rheological velocities at different depths within the stress range of the surrounding rock of the roadway are different, and the rheological rate near the wall of the roadway is relatively large, and the rheological rate of the deep surrounding rock is relatively small due to the high confining pressure.
3.2.3. Unloading Confining Pressure with Axial Compression. The unloading confining pressure with axial compression triaxial test results of mudstone is shown in Figure 9. With increasing deviating stress, the axial and lateral instantaneous strain increments of a mudstone specimen decrease gradually, and the lateral rheological strain and velocity of 


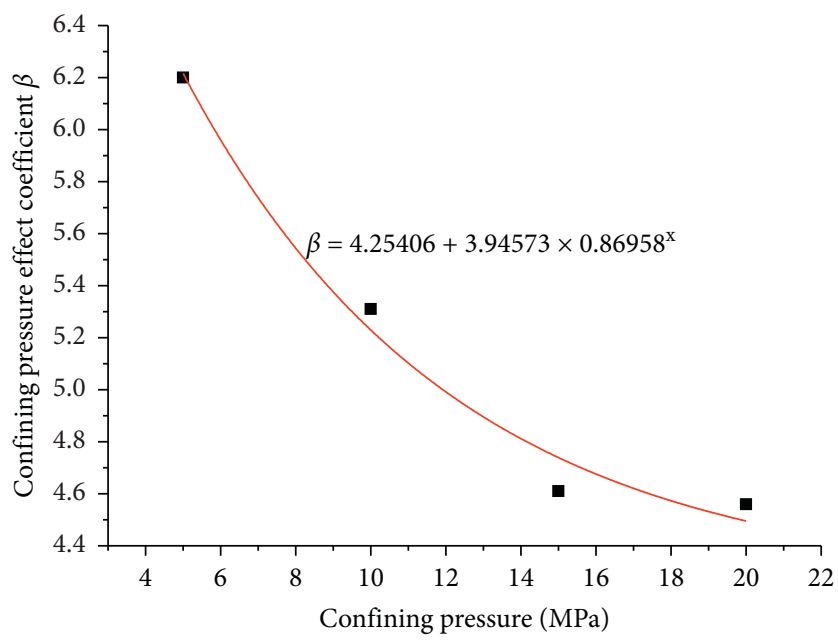

FIGURE 6: Relation curve between confining pressure effect coefficient and confining pressure.

TABLE 6: Confining pressure effect coefficients.

\begin{tabular}{|c|c|c|c|c|c|}
\hline Confining pressure & $\sigma_{3}(\mathrm{MPa})$ & 5 & 10 & 15 & 20 \\
\hline Peak strength & $\sigma_{1}(\mathrm{MPa})$ & 68.27 & 90.4 & 106.41 & 128.43 \\
\hline Confining pressure effect coefficient & $\beta$ & 6.20 & 5.31 & 4.61 & 4.56 \\
\hline
\end{tabular}

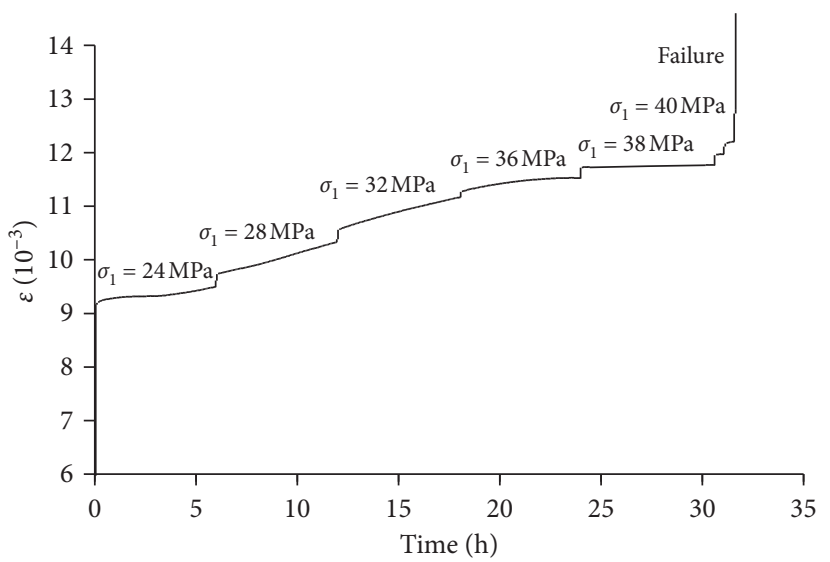

(a)

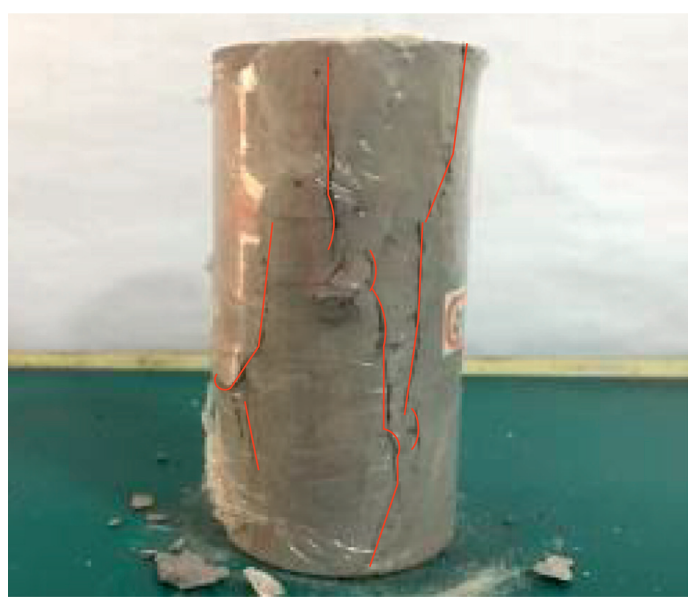

(b)

Figure 7: Uniaxial rheological test results of mudstone. (a) Strain-time curve. (b) Failure form of mudstone.

mudstone specimen increase gradually. The lateral deformation characteristics of the specimen are more significant than those of the axial ones, and the lateral dilatancy effect is obvious. The lateral rheological amount is approximately 2.05 times the axial rheological amount. When the applied deviatoric stress is less than the lower yield value and the change of the deviatoric strain with time is limited, corresponding to the finite rheology, the rheological rate is relatively slow. When the applied deviator stress is larger and exceeds the upper yield value, the rheology belongs to the destructive rheology, and the rheological effect is the most obvious and the rate is fast.

As shown in Figure 10, the failure form of the unloading confining pressure with an axial compression triaxial test of mudstone is the same as that of unloading confining pressure with a constant axial pressure triaxial test, both of which are shear failure, and the shear failure angle is approximately $60^{\circ}$. 

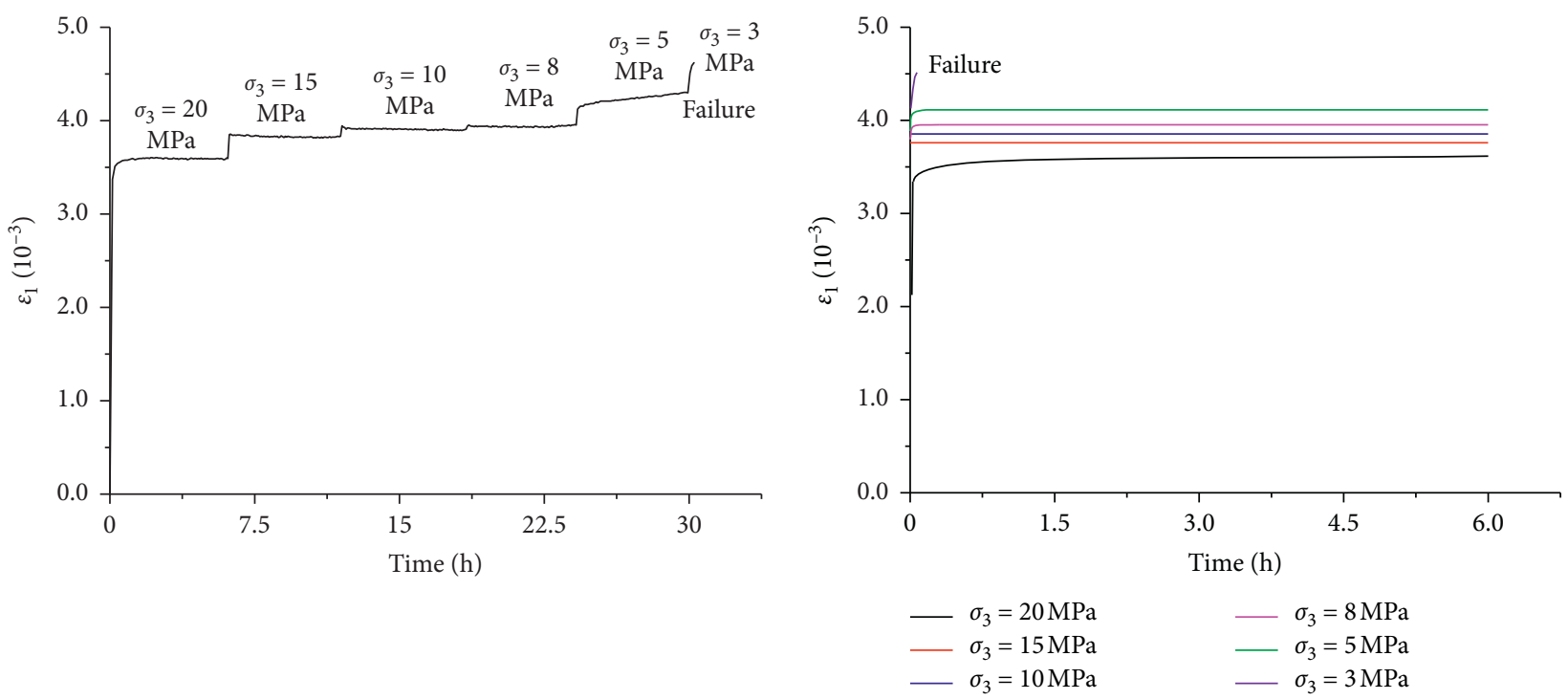

(a)
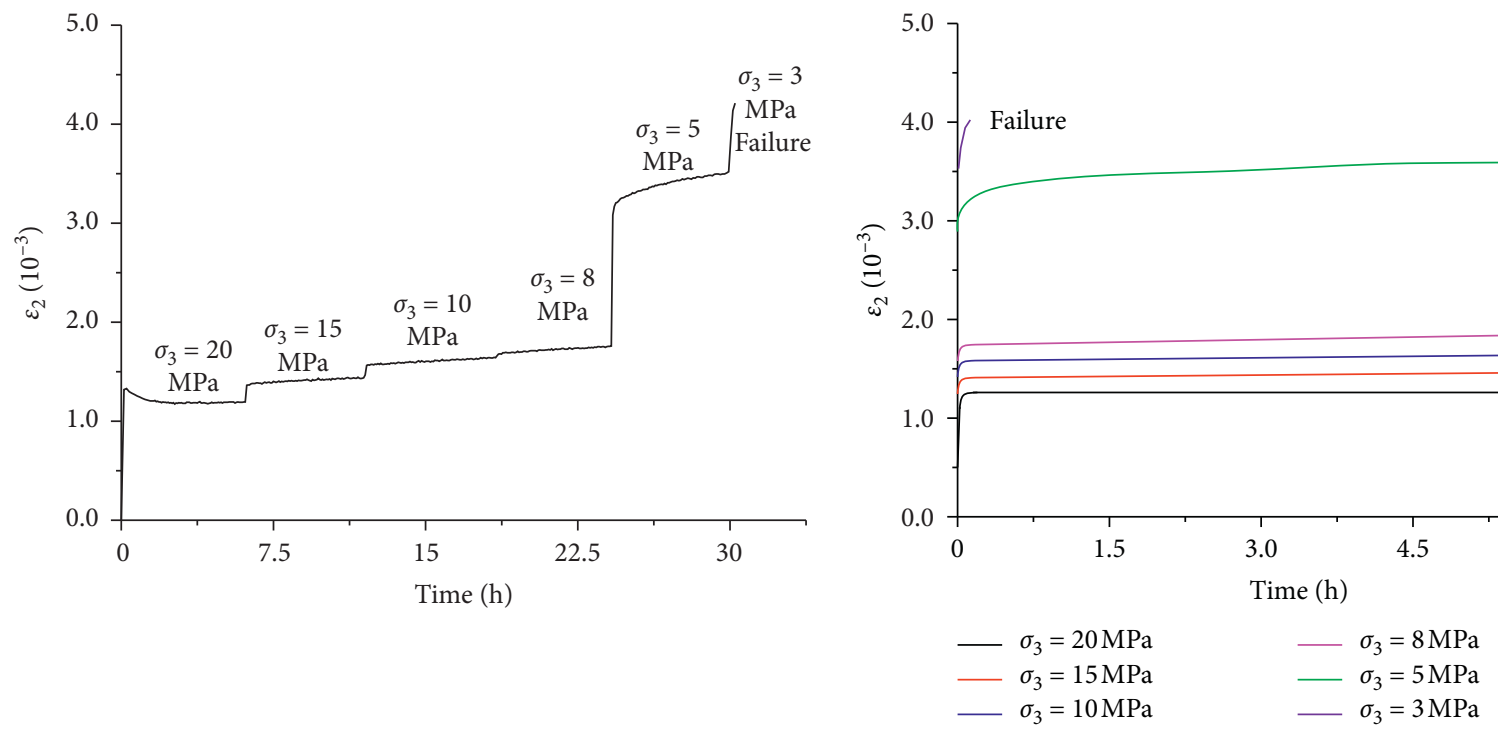

(c)

(d)

Figure 8: Unloading confining pressure with constant axial pressure triaxial test results of mudstone. (a) Change of axial strain with time. (b) Isochronous curves of axial strain. (c) Change of lateral strain with time. (d) Isochronous curves of lateral strain.

From the perspective of lithology, mudstone is the main rock formation for the rheological damage of the surrounding rock of the roadway; when the confining pressure is unloaded by axial pressure, the rheological effect is the most obvious, followed by the constant axial pressure and unloading the confining pressure, and the minimum is the uniaxial pressure. The rheological effect is the most significant when affected.

\subsection{Influence on Deformation and Failure}

3.3.1. Deep Failure Form. The stress environment of the surrounding rock mass of a kilometer-deep mine is quite different in different periods after excavation and so is the corresponding deep failure form of the surrounding rock
[16]. As shown in Figure 11, test A refers to unloading confining pressure with axial compression triaxial test. Test $\mathrm{B}$ refers to unloading confining pressure with constant axial pressure triaxial test. Test $\mathrm{C}$ refers to uniaxial rheological test. In test $\mathrm{A}$, the axial deformation of mudstone increases linearly with increasing deviating stress, while the lateral deformation increases exponentially, and the axial deformation is 1.51 times the lateral deformation. In test $\mathrm{B}$, the axial and lateral deformations of mudstone increase linearly with increasing deviating stress, the lateral deformation appears to accelerate before the failure, and the axial deformation is 1.22 times the lateral deformation. In test $\mathrm{C}$, the axial deformation increases nonlinearly with increasing deviating stress, and the deformation speed decreases gradually. 


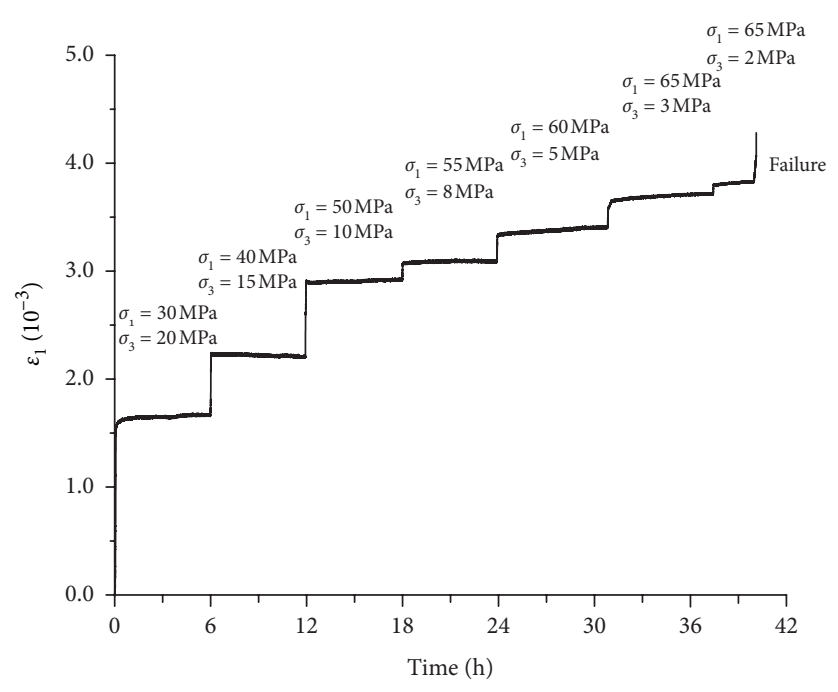

(a)

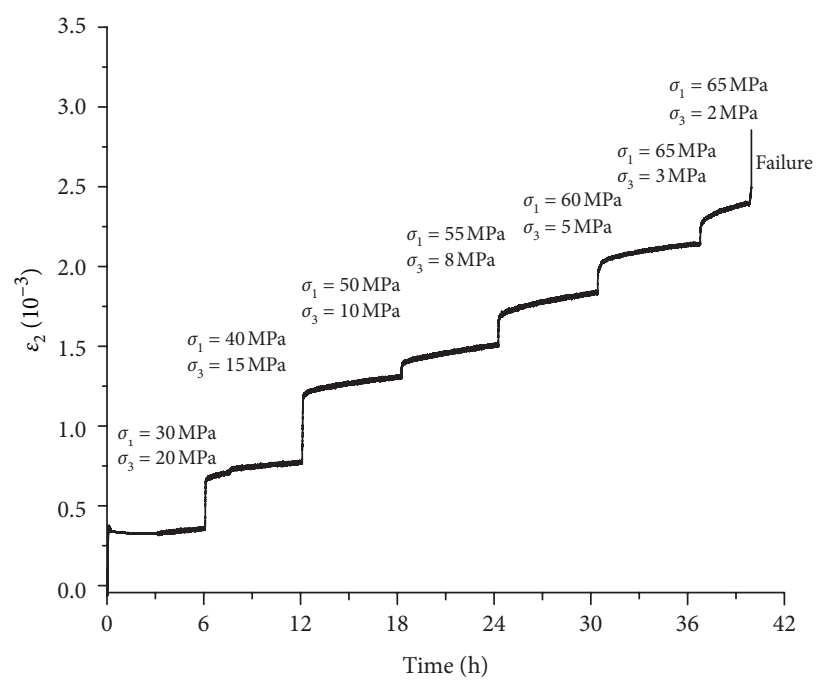

(c)

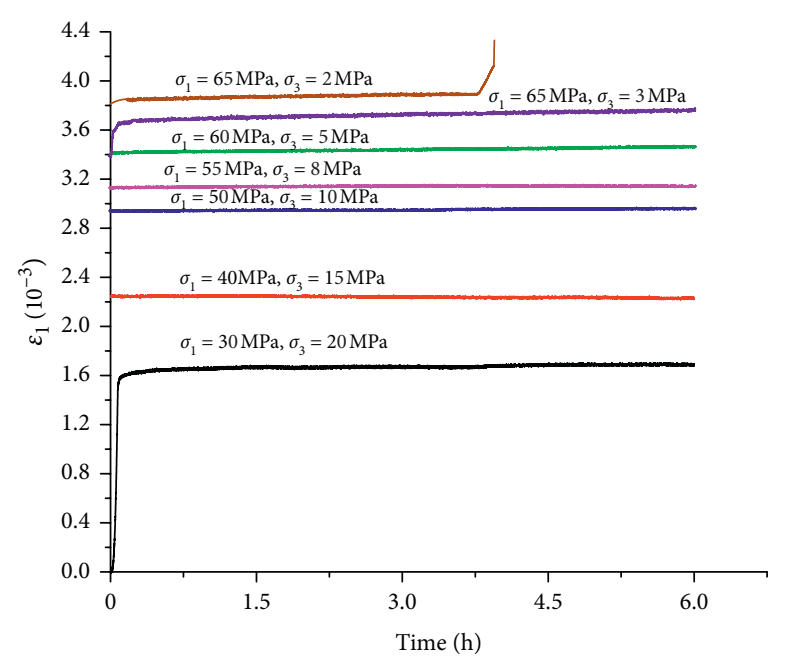

(b)

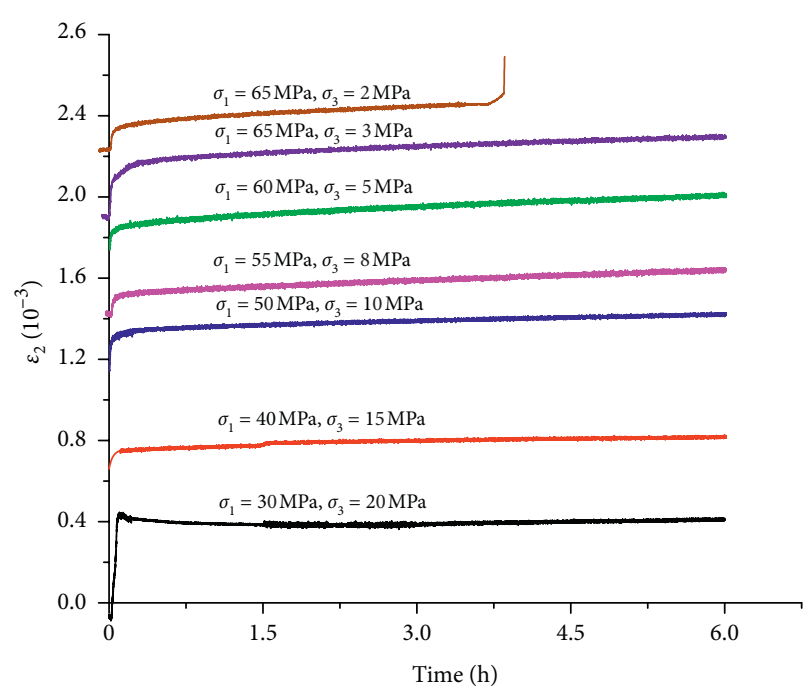

(d)

FIGURE 9: Unloading confining pressure with axial compression triaxial test results of mudstone. (a) Change of axial strain with time. (b) Isochronous curves of axial strain. (c) Change of lateral strain with time. (d) Isochronous curves of lateral strain.

Table 7 shows the failure form and maximum deviating stress value for the mudstone rheological test. First, the failure form of the mudstone specimen in the uniaxial rheological test is split failure, and the failure form in other two types of tests is shear failure. Second, the peak value of the deviating stress of the specimen in the uniaxial rheological test is the lowest, that is, $40 \mathrm{MPa}$; the peak value of the deviating stress of the specimen in the unloading confining pressure with axial compression rheological test is the highest, that is, $63 \mathrm{MPa}$.

Referring to the failure form in Table 7, the lateral unloading of surrounding rock occurs at the same time as the increase of the vertical stress during the period affected by driving, and the main failure form of surrounding rocks is the shear failure. The lateral unloading of surrounding rock occurs under the condition of constant vertical stress, and the main failure form is also the shear failure. During the period affected by mining, vertical loading occurs when lateral unloading has basically ended, and the main failure form is splitting failure. Then, according to the maximum deviating stress that the surrounding rock of roadway can bear, the surrounding rock is most likely to be damaged during the period affected by mining.

3.3.2. Internal Rheological Deformation. The in situ stress of the surrounding rock in a kilometer-deep mine is almost close to or over the failure strength of the rock mass. The excavation and unloading of a roadway will increase the stress field of surrounding rock and make the cracks or joints that are originally in a stable state in the rock mass open, expand, or even connect, significantly changing the mechanical properties of the rock mass in the area disturbed by excavation [17, 18]. Figure 12 shows the rheological strain curve of mudstone changing with deviating stress, and Table 8 presents the statistics of rheological strain at the first 


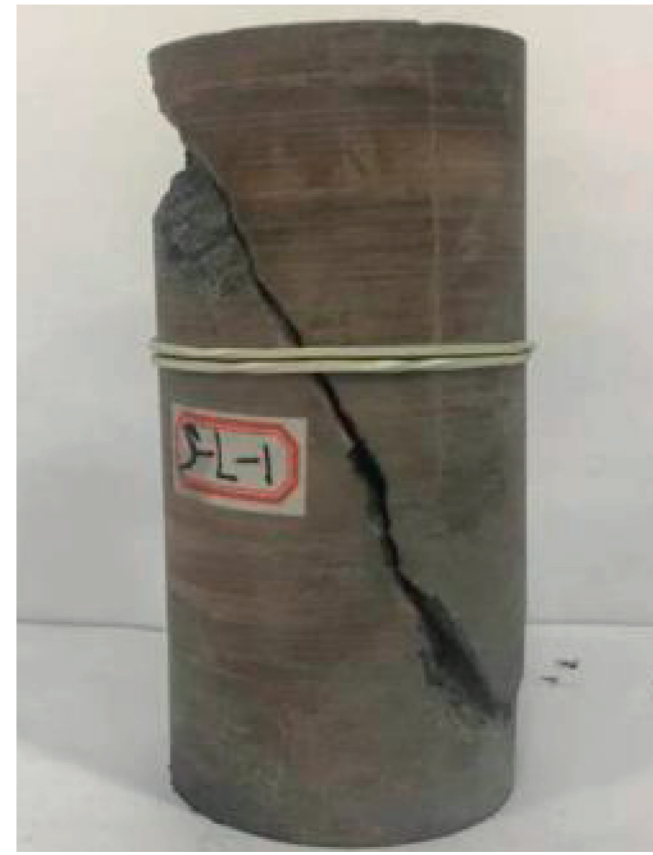

(a)

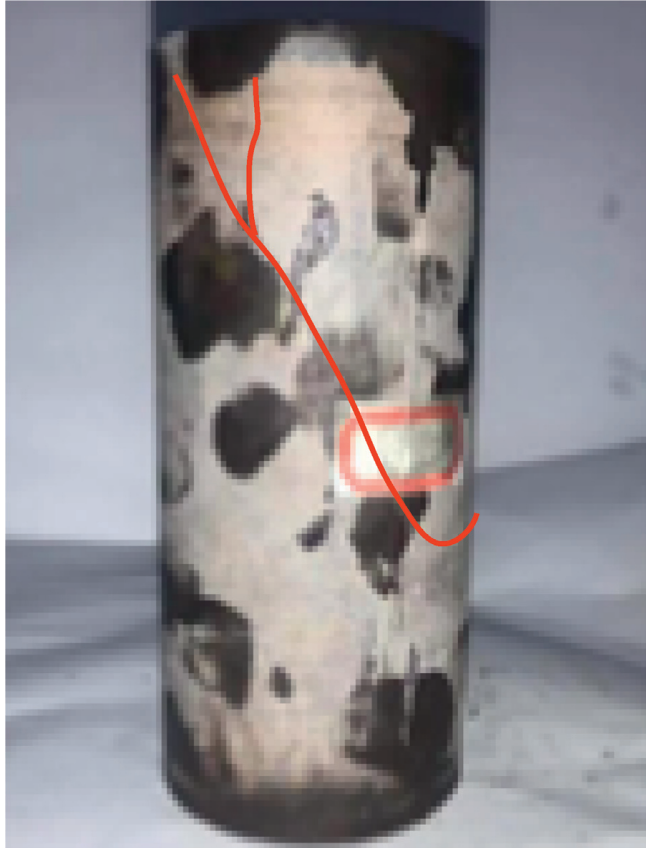

(b)

FIGURE 10: Failure morphology of mudstone in triaxial rheological test. (a) Unloading confining pressure with constant axial pressure. (b) Unloading confining pressure with axial compression.

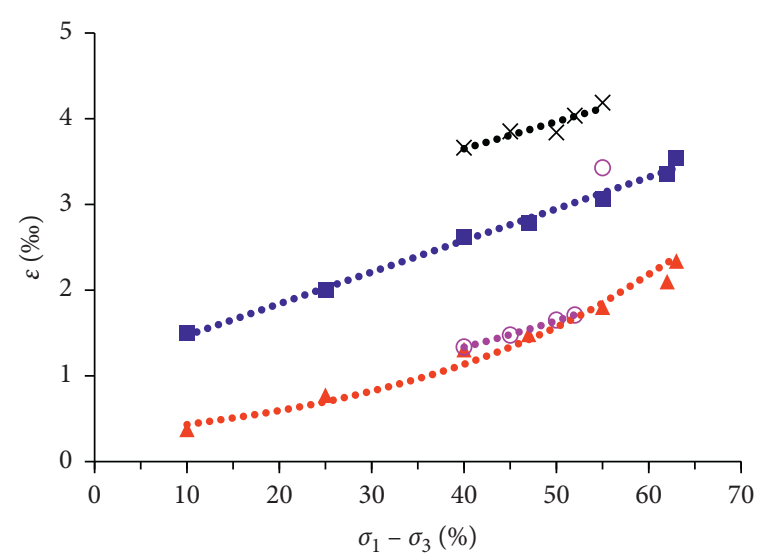

- Test A-axial strain A Test A-lateral strain

$\times$ Test B-axial strain O Test B-lateral strain

(a)

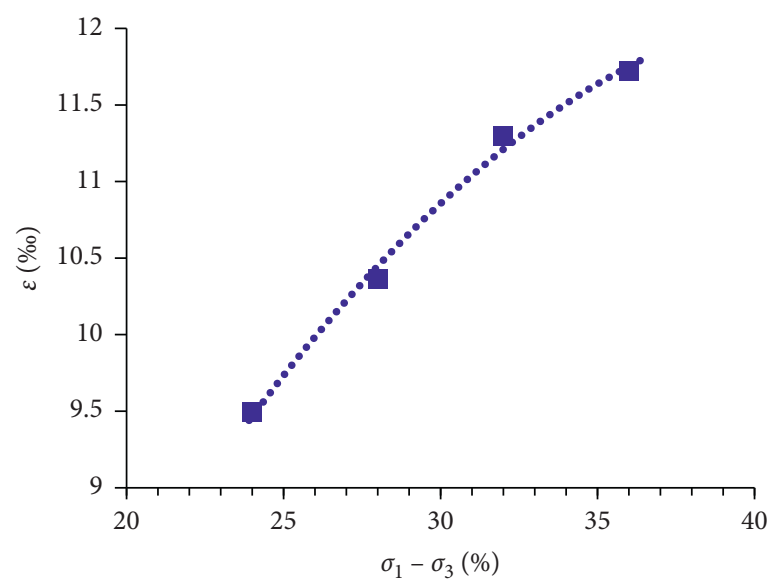

Test C-axial strain

(b)

FIgURE 11: Variation curves of mudstone deformation with deviating stress. (a) Triaxial rheological test. (b) Uniaxial rheological test.

grade load before the failure of the specimen. From the triaxial rheological test of mudstone, it can be seen that the rheological deformation of mudstone in a kilometer-deep mine is dominated by deviating stress, and the high level of confining pressure has a restraining effect on the axial and lateral rheologies of the rock, so its rheological deformation is small. After roadway excavation or under the influence of mining, the stress environment of surrounding rock changes, the deviating stress of rock increases, and the rock mass exhibits rheological deformation.
It can be seen in Figure 12 and Table 8 that the rheological deformation of the specimen in the above three rheological tests increases nonlinearly with increasing deviating stress. In test $\mathrm{A}$, the axial and lateral rheological deformations of mudstone increase exponentially with increasing deviating stress, and the lateral rheological deformation is approximately 2.05 times the axial rheological deformation. Therefore, during the period affected by the driving of a roadway in a kilometer-deep mine, the internal rheological deformation of surrounding rock mainly occurs 
TABLE 7: Failure modes of mudstone rheological test specimen.

\begin{tabular}{|c|c|c|c|}
\hline Stress environment & Type of rheological test & $\begin{array}{l}\text { Failure form of } \\
\text { test piece }\end{array}$ & $\begin{array}{c}\text { Maximum deviating stress }\left(\sigma_{1}-\sigma_{3}\right) \\
(\mathrm{MPa})\end{array}$ \\
\hline $\begin{array}{l}\text { Period affected by } \\
\text { driving }\end{array}$ & $\begin{array}{l}\text { A-unloading confining pressure with axial } \\
\text { compression rheological test }\end{array}$ & Shear failure & 63 \\
\hline $\begin{array}{l}\text { Period affected by stable } \\
\text { driving }\end{array}$ & $\begin{array}{l}\mathrm{B} \text { - unloading confining pressure with constant axial } \\
\text { pressure rheological test }\end{array}$ & Shear failure & 57 \\
\hline $\begin{array}{l}\text { Period affected by } \\
\text { mining }\end{array}$ & C-uniaxial rheological test & Splitting failure & 40 \\
\hline
\end{tabular}

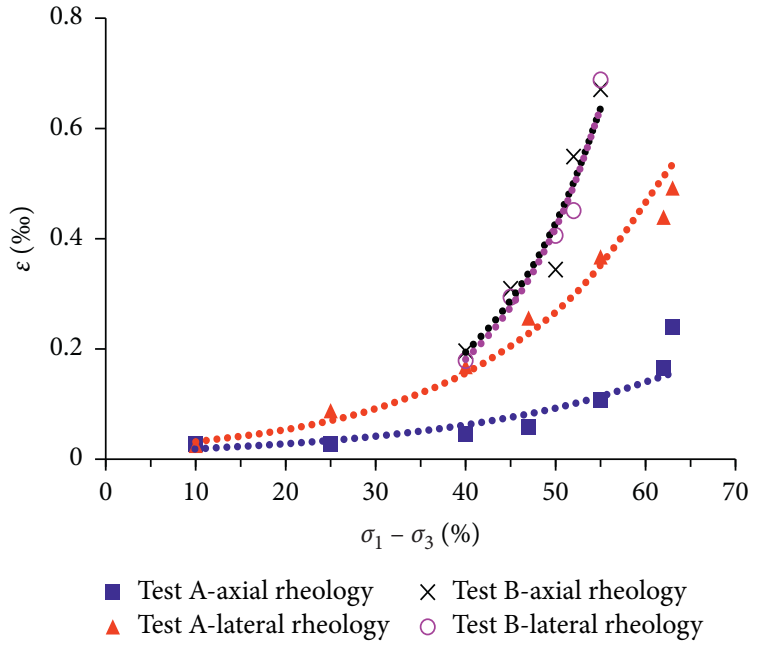

(a)

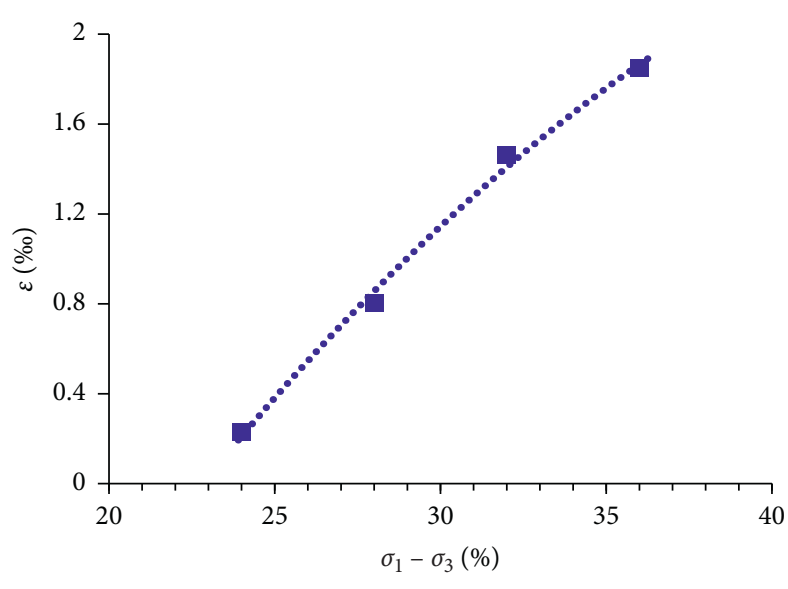

Test C-axial rheology

(b)

FIGURE 12: Variation curves of mudstone rheology with deviating stress. (a) Rheological strains of mudstone in triaxial rheological test. (b) Rheological strain of mudstone in uniaxial rheological test.

TABLE 8: Rheological strains of mudstone rheological test specimen.

\begin{tabular}{|c|c|c|c|c|}
\hline Stress environment & Type of rheological test & $\begin{array}{l}\text { Lateral } \\
\text { rheology }(\% 0)\end{array}$ & $\begin{array}{c}\text { Axial rheology } \\
(\% 0)\end{array}$ & $\begin{array}{l}\text { Maximum deviating stress } \\
\left(\sigma_{1}-\sigma_{3}\right)(\mathrm{MPa})\end{array}$ \\
\hline $\begin{array}{l}\text { Period affected by } \\
\text { driving }\end{array}$ & $\begin{array}{l}\text { A-unloading confining pressure with axial } \\
\text { compression rheological test }\end{array}$ & 0.492 & 0.24 & 63 \\
\hline $\begin{array}{l}\text { Period affected by } \\
\text { stable driving }\end{array}$ & $\begin{array}{l}\text { A-unloading confining pressure with constant } \\
\text { axial pressure rheological test }\end{array}$ & 0.688 & 0.671 & 55 \\
\hline $\begin{array}{l}\text { Period affected by } \\
\text { mining }\end{array}$ & $\mathrm{B}$ - uniaxial rheological test & - & 1.849 & 40 \\
\hline
\end{tabular}

on the unloading side. In test $B$, the axial stress of the specimen is always maintained at a high level, and the deformation of axial and lateral flows is nonlinear and the difference between them is small, indicating that the internal rheological deformation of the surrounding rock increases synchronously in the axial and lateral directions in the period affected by stable driving in a kilometer-deep mine. In test $\mathrm{C}$, the axial rheological deformation of the specimen increases with increasing axial pressure, and the rheological velocity is larger than those in the other two kinds of rheological tests. The axial rheological deformations are 7.70 times that of the unloading confining pressure with axial compression rheological test and 2.76 times that of the unloading confining pressure with constant axial pressure rheological test. The specimen is damaged when the axial pressure reaches the uniaxial compressive strength of rock.

\section{Discussion}

The mining impact period is the most rapid development period of the rheological deformation of the surrounding rock in a kilometer-deep mine, and it is easy for rheological deformation to develop into destructive deformation. In order to further research the rheological deformation characteristics of the surrounding rock of the kilometerdeep mine, the next step is to study the mineral composition, porosity, microstructure, and other characteristics of the mudstone through laboratory tests and to study rheological 
characteristics of surrounding rock of deep mine roadway from a microscopic point of view.

\section{Conclusions}

In view of the rheological problems of mudstone in a kilometer-deep mine, triaxial loading, uniaxial rheological, unloading confining pressure with constant axial pressure rheological, and unloading confining pressure with axial compression rheological test were carried out in the laboratory. The main conclusions are the following:

(1) The peak strength of the triaxial compression of mudstone is closely related to the surrounding rock. With increasing confining pressure, the difference between peak and residual strength decreases gradually, and the confining pressure effect gradually weakens.

(2) The strain of the specimen increases slowly in the uniaxial loading test. With increasing axial pressure, the velocity of rheological deformation increases nonlinearly.

(3) In the unloading confining pressure with constant axial pressure rheological test, with the gradual decrease of confining pressure, the axial and radial instantaneous strains of the mudstone specimen increase nonlinearly, the rheological strain and rheological speed of mudstone increase gradually, and the lateral rheology variable is basically the same as the axial rheology variable.

(4) With increasing deviating stress, the axial and lateral instantaneous strain increments of the mudstone specimen decrease gradually, and the lateral rheological strain and velocity of the mudstone specimen increase gradually. The lateral rheological amount is approximately 2.05 times the axial rheological amount.

(5) The internal rheology of the surrounding rock in a kilometer-deep mine is mainly dominated by deviating stress. The increase of deviating stress results in the acceleration of the rheology of mudstone. The surrounding rock is prone to incur shear failure in the period affected by driving, and split failure is prone to occur in the period affected by mining.

\section{Data Availability}

The data used to support the findings of this study are available from the corresponding author upon request.

\section{Conflicts of Interest}

The authors declare that they have no conflicts of interest.

\section{Acknowledgments}

This work was financially supported by State Key Research Development Program of China (no. 2017YFC0603001), the National Natural Science Foundation of China (nos.
51704181 and 51809160), and Major Program of Shandong Provincial Natural Science Foundation (ZR2018ZA0603).

\section{References}

[1] H. P. Kang, G. F. Wang, P. F. Jiang et al., "Conception for strata control and intelligent mining technology in deep coal mines with depth more than $1000 \mathrm{~m}$," Journal of China Coal Society, vol. 43, no. 7, pp. 1789-1800, 2018.

[2] R. D. Peng, D. J. Xue, H. F. Sun et al., "2.19. Characteristics of strong disturbance to rock mass in deep mining," Journal of China Coal Society, vol. 44, no. 5, pp. 1359-1368.

[3] H. P. Kang, B. D. Yi, F. Q. Gao, and H. Lü, "Database and characteristics of underground in-situ stress distribution in Chinese coal mines," Journal of China Coal Society, vol. 44, no. 1, pp. 23-33, 2019.

[4] Z. X. Cai, W. J. Liu, Y. D. Qin et al., "Exploration of measurement of distribution rule of in situ stress in the depth below 1000 m," China Mining Magazine, vol. 28, no. s1, pp. $275-278,2019$.

[5] Q. Liu, M. Z. Gao, M. Wang et al., "Study on rock pressure behavior law and overburden displacement characteristics of mining face at $1000 \mathrm{~m}$ depth," Chinese Journal of Rock Mechanics and Engineering, vol. 38, no. S1, pp. 3070-3079, 2019.

[6] Y. F. Gao, Z. J. Qu, J. L. Niu et al., "Rheological law for soft rock tunnel and evolution law for stress field in deep mine," Journal of China Coal Society, no. 12, pp. 1244-1252, 2007.

[7] X. F. Yuan, H. F. Deng, J. L. Li et al., "Unloading rheological constitutive model for sandy mudstone," Chinese Journal of Rock Mechanics and Engineering, vol. 37, no. 9, pp. 1733-1739, 2015.

[8] B. Wang, "Study on rheological properties of soft rock roadways in longkou sea area," Journal of North China Institute of Science and Technology, vol. 13, no. 1, pp. 62-65, 2016.

[9] L. J. Wang, H. W. Zhou, T. L. Rong et al., "Stress field evolution law and disturbance characteristic of coal at depth under mining," Chinese Journal of Rock Mechanics and Engineering, vol. 38, no. S1, pp. 2944-2954, 2019.

[10] H. W. Jing, Q. Yin, D. Zhu et al., "Experimental study on the whole process of instability and failure of anchorage structure in surrounding rock of deep-buried roadway," Journal of China Coal Society, vol. 45, no. 3, pp. 889-901, 2020.

[11] L. J. Wang, H. W. Zhou, T. L. Rong et al., "Research on experimental and nonlinear creep constitutive model of coal at depth," Journal of China Coal Society, vol. 43, no. 8, pp. 2196-2203, 2018.

[12] T. B. Zhao, Y. B. Zhang, Y. L. Tan et al., "Simulation analysis on creep failure of deep bolting roadways considering the effect of damage," Journal of Mining \& Safety Engineering, vol. 31, no. 5, pp. 709-715, 2014.

[13] T. B. Zhao, Y. D. Jiang, Y. B. Zhang, and S.-S. Liu, "Secondary development and engineering application of viscoelastoplastic BK-MC anchorage model," Rock and Soil Mechanics, vol. 35, no. 3, pp. 278-283+292, 2014.

[14] W. Y. Guo, F. H. Yu, and Y. L. Tan, T. B. Zhao, "Experimental study on the failure mechanism of layer-crack structure," Energy Science \& Engineering, vol. 7, no. 6, pp. 2351-2372, 2019.

[15] Y. L. Tan, W. Y. Guo, T. B. Zhao, and X. J. Meng, "Study on the mechanism and "Discharge-Fixation" collaborative control of the instability induced flushing of deep coal Roadway," Journal of China Coal Society, vol. 45, no. 1, pp. 66-81, 2020. 
[16] M. Wang, Y. H. Niu, Y. J. Yu et al., "Experimental research on characteristics of deformation and failure of surrounding rock of roadway in deep mine under influence of principal stress evolution," Chinese Journal of Rock Mechanics and Engineering, vol. 38, no. 2, pp. 237-244, 2016.

[17] L. Li, J. Hu, S. Li et al., "Development of a novel triaxial rock testing method based on biaxial test apparatus and its application," Rock Mechanics and Rock Engineering, 2021.

[18] Q. Gao, Q. Y. Zhang, X. T. Zhang et al., "Zonal disintegration mechanism analysis based on strain gradient of deep surrounding rock mass under dynamic unloading effect," Rock and Soil Mechanics, vol. 39, no. 9, pp. 3181-3194, 2018. 